\title{
Desenvolvimento de Jogo Educacional sobre Ecotoxicologia Utilizando HTML5
}

\author{
Title: Development of Educational Game about Ecotoxicology on HTML5
}

\author{
Diogo Moreira Bispo \\ Faculdade de Tecnologia - Universidade Estadual de \\ Campinas (FT - UNICAMP) \\ Limeira, SP \\ diogobispo@gmail.com
}

Gisela Aragão Umbuzeiro

Faculdade de Tecnologia - Universidade Estadual de Campinas (FT - UNICAMP)

Limeira, SP

giselau@usp.br

\author{
Márcio Silvatti Zabeu \\ Faculdade de Tecnologia - Universidade Estadual de \\ Campinas (FT - UNICAMP) \\ Limeira, SP \\ marciozabeu@gmail.com
}

Marcos Augusto Francisco Borges

Faculdade de Tecnologia - Universidade Estadual de Limeira, SP

marcosborges@ft.unicamp.br

Resumo Este trabalho foi desenvolvido para auxiliar no ensino de conceitos de toxicologia ambiental para os alunos de Saneamento Ambiental da Faculdade de Tecnologia da UNICAMP. Para tanto, foi desenvolvido um jogo educativo para ensinar o ciclo de vida e o uso de microcrustáceos do gênero Daphnia.

Este jogo foi criado em HTML5, visando verificar a possibilidade de se utilizar esta tecnologia para o desenvolvimento de jogos educacionais.

Palavras-Chave: Jogos Educativos, Daphnia, HTML5, Toxicologia Ambiental

\begin{abstract}
This paper was developed for teaching environmental toxicology concepts to undergraduate students of environmental sanitation of the College of Technology of UNICAMP. For this purpose an educational game was developed to teach the Daphnia's life cycle and uses.

This game was developed in HTML5, aiming to verify the possibility of developing educational games with this technology.
\end{abstract}

Keywords: Educational Games, Daphnia, Environmental Toxicology 


\section{Introdução}

A área de Toxicologia Ambiental é um ramo da Toxicologia que estuda situações de exposição a agentes químicos em nosso meio. Estuda-se as reações adversas em um ambiente de acordo com o grau de exposição (concentração química e período de tempo de exposição) a emissões de diversas naturezas e seus possíveis impactos [1].

Problemas no conhecimento de conceitos de Toxicologia foram identificados por Monro [2] . De acordo com ele, alguns conceitos como o de risco, de perigo e de dose-resposta, deveriam ser conhecidos pelo grande público, por serem úteis em atividades diárias, como a escolha de alimentos em supermercados, mas esses conceitos são apresentados de forma incorreta pelos meios de comunicação de massa.

Estes problemas também foram identificados no ensino da matéria de Toxicologia Ambiental do curso de Tecnologia de Saneamento Ambiental, ministrado na Faculdade de Tecnologia da Unicamp e motivaram o desenvolvimento de um jogo educativo, o Daphnia Wor$l d$, em que o jogador controla um animal muito utilizado em estudos de Toxicologia Ambiental. O jogo tem como objetivo apoiar o ensino de ecotoxicologia.

O jogo foi criado a partir de uma parceria entre o Laboratório de Ecotoxicologia e Microbiologia Ambiental Prof $^{\circ}$ Dr. Abílio Lopes (LEAL) e o Laboratório de Informática Aprendizado e Gestão (LIAG).

Este trabalho está divido da seguinte forma: o capítulo 2 apresenta alguns conceitos de Toxicologia Ambiental, o capítulo 3 faz uma breve introdução sobre jogos educativos, o capítulo 4 apresenta os materiais e métodos do trabalho, o capítulo 5 apresenta os resultados e o capítulo 6 apresenta a conclusão .

\section{Daphnia e Toxicologia Ambiental}

A Toxicologia Ambiental é, de acordo com Williams et al. [1]: "um ramo da toxicologia dedicado ao estudo de situações de exposições químicas encontradas no nosso meio. Estas exposições podem advir da aplicação de substâncias químicas na agricultura (como pesticidas, reguladores de crescimento, fertilizantes), o despejo de substâncias químicas durante nossa vida moderna (substâncias lançadas por casas), despejos industriais regulamentados e inintencionais no ar e nos rios e várias fontes de emissão pequenas (como os subprodutos da combustão nos carros)".

Testes de toxicidade estão entre os métodos da Toxicologia Ambiental para estudar os efeitos de exposições no meio. Este tipo de teste utiliza um agente biológico para determinar o grau de toxicidade de em determinado ambiente, em condições reprodutíveis [1].

A Daphnia é um gênero de microcrustáceos, sendo que algumas espécies (Daphnia magna e Daphnia pulex) são utilizadas como agentes biológicos em testes de toxicidade. Existem dois tipos de testes de toxicidade que podem ser feitos com a Daphnia: teste agudo e teste crônico. O primeiro serve para medir o quão agudo são os efeitos de determinados efluentes em água doce, enquanto o segundo mede os efeitos sobre a reprodução dos indivíduos [3].

\section{Jogos Educativos}

Com o advento do computador, novas formas de se trabalhar o ensino e a aprendizagem se tornaram possíveis, com a interação dos alunos com a máquina [4]. O computador pode ser utilizado tanto de forma instrucionista, atuando assim como um transmissor de informações, como também de forma construtivista e construcionista, em que o aluno pode construir o próprio conhecimento, tendo a máquina como ferramenta $[4,5]$. O construtivismo tem sido visto como uma abordagem necessária para o processo de ensino-aprendizagem [6].

Os jogos educativos são uma ferramenta para o aprendizado construtivista [6]. Rieber [7] afirma que há 'pesquisas extensas sobre 'brincar' em antropologia, sociologia e educação, como um importante mediador para o aprendizado e a socialização pela vida". Como exemplo, há a linguagem de programação LOGO, criado por Papert, onde podem ser trabalhados uma variedade de conceitos geométricos e físicos [7].

De acordo com Bittencourt e Giraffa [6], para o planejamento de um jogo educativo, deve-se "definir e fixar os objetivos da atividade, a determinação do contexto desejado para a mesma, a identificação dos recursos utilizáveis para se alcançar os objetivos finais e a determinação da sequência de interações".

\section{Materiais e Métodos}

Este capítulo apresenta os materiais e métodos do trabalho. A primeira seção descreve as tecnologias utilizadas para a criação do jogo; a segunda seção descreve o desenvolvimento das diferentes partes do jogo; a terceira discute os materiais associados à edição gráfica do jogo e a última discute o processo de design da interface.

O jogo foi criado para ser jogado pela Internet, com o uso de um navegador. Optou-se pela plataforma web por ela ser de fácil distribuição e acessível, uma vez que não é necessário instalações e pode-se jogar a partir de qualquer computador com um navegador web e conectado à Internet. 
O jogo foi desenvolvido em HTML5, utilizando-se a linguagem ECMAscript. O jogo é compatível com as mais recentes versões dos navegadores mais utilizados do mercado (Google Chrome 6+, Mozilla Firefox 3.6+ e Microsoft Internet Explorer 9) [8]. A seção 4.1 discute o uso de HTML5.

O desenvolvimento do jogo foi dividido em duas partes: Engine e Jogo. A Engine possui funcionalidades e componentes comuns a diversos jogos, enquanto a parte do Jogo possui elementos específicos do Daphnia World. Na seção 4.2 é apresentada a Engine, enquanto na seção 4.3 apresenta-se a parte específica do jogo. A seção 4.4 irá discutir a criação das imagens do jogo e a seção 4.5 apresenta algumas considerações sobre o design da interface.

\subsection{HTML5 e DHTML}

A Linguagem Dinâmica de Marcação de Hipertexto (Dynamic HyperText Markup Language - DHTML) é um conjunto de tecnologias: uma linguagem de marcação, como a Linguagem de Marcação de Hipertexto (HyperText Markup Language - HTML), o Modelo de Documentos baseado em Objetos (Document Object Model - DOM), as Folhas de Estilo em Cascata (Cascading Style Sheets - CSS) e a linguagem de script ECMAscript, que combinadas permitem a criação de interfaces web mais interativas [9].

Quando a DHTML é combinada com o "Javascript e XML Assíncrono" (Asynchronous Javascript and XML Ajax), minimiza-se o número de atualizações das páginas, dando-lhes assim uma maior interatividade e diminuindo o tempo de resposta da aplicação aos comandos do usuário. O conjunto das novas versões em desenvolvimento do HTML e do CSS, e de novas Interfaces para a Programação de Aplicações (Application Program Interface - API) para ECMAScript tem sido chamadas de HTML5 [10].

O Modelo de Documentos baseados em Objetos (DOM) é uma Interface para a Programação de Aplicações criada para a manipulação dos documentos de hipertexto descritos em HTML ou outras linguagens [11]. O navegador, ao acessar um documento de hipertexto, monta internamente uma estrutura DOM que pode ser manipulada por scripts ECMAscript.

A linguagem HTML, desenvolvida em 1989, é uma linguagem baseada em marcas, onde palavras-chave indicam o início e o fim de cada elemento do hipertexto. Estas marcas podem ser aninhadas, formando estruturas complexas, capazes de descrever uma estrutura DOM.

Folhas de Estilo em Cascata (CSS) são um mecanismo utilizado para se controlar a aparência de páginas Web. Enquanto o DOM trata da estrutura do documento, questões como cor, posição dos elementos, efeitos de negrito e itálico, tamanho e estilo das letras ficam por conta das CSS. Esta tecnologia se tornou o padrão devido a possibilidade de se combinar diversas folhas de estilo para compor a aparência final do documento [12].

ECMAscript é uma linguagem de script criada para a manipulação de objetos DOM. É um padrão criado pela European Computer Manufacturers Association (ECMA) fortemente baseado na linguagem Javascript criada pela Netscape e suas variações implementadas em outros navegadores [13].

\subsection{Engine}

Uma engine é uma biblioteca com elementos e funcionalidades que auxiliam no desenvolvimento de jogos [14]. Para que o desenvolvimento de outros jogos fosse facilitado, optou-se por criar uma engine que possuísse recursos que fossem usuais para o tipo de jogos educativos usualmente criados no grupo de pesquisas em que este projeto foi desenvolvido.

A engine criada durante o desenvolvimento deste trabalho controla a exibição dos elementos na tela. Para que isto seja possível, foi programada uma estrutura baseada em camadas transparentes de tamanho infinito e que ficam uma acima da outra. Em cada camada ficam os elementos visuais do jogo, e como as camadas são transparentes, o que está em uma camada superior sobrepõe o que está em uma camada inferior. Assim é possível que os personagens do jogo, por exemplo, fiquem acima do cenário.

Outra funcionalidade desenvolvida para a engine foi a linha do tempo, formada por quadros. A engine possui um contador de tempo, que pode ser ligado e desligado, que faz com que a exibição vá passando por todos os quadros da linha do tempo. Com esse recurso, o jogo que utiliza a engine pode estabelecer em qual momento temporal do jogo determinado evento vai ocorrer.

Por fim, foi também adicionada uma "câmera" à engine, um objeto responsável por selecionar uma área do jogo para exibição. As camadas possuem tamanho infinito, porém o canvas, onde o jogo é exibido, possui um tamanho finito. A câmera funciona então como um controle para definir qual região das camadas será exibida. A Figura 1 mostra o diagrama de classes da Engine. 


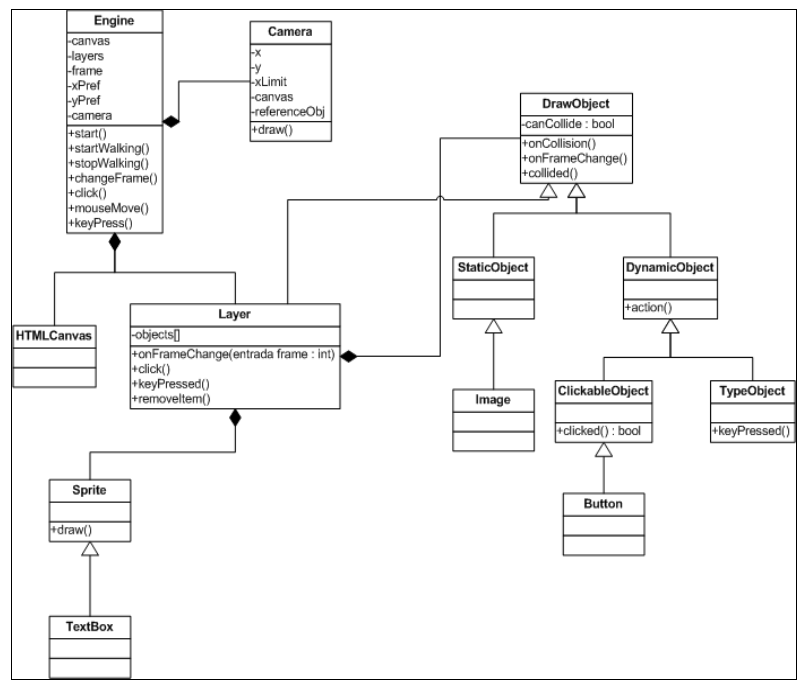

Figura 1: Diagrama de Classes da Engine

\subsection{Jogo}

Com uma engine controlando tempo e espaço, o desenvolvimento do jogo foi facilitado. $\mathrm{O}$ jogo foi estruturado de acordo com seus possíveis estados. O estado inicial é o "Início", representado por classe de mesmo nome, onde é exibida a tela inicial do jogo. Do estado "Jogando", o jogo pode ir para o estado "Vitória" (classe "Vitoria") ou para o estado "Derrota" (classe "Derrota"). Qualquer um desses dois estados termina o jogo. A Figura 2 mostra um diagrama de estado esquematizando os estados possíveis.

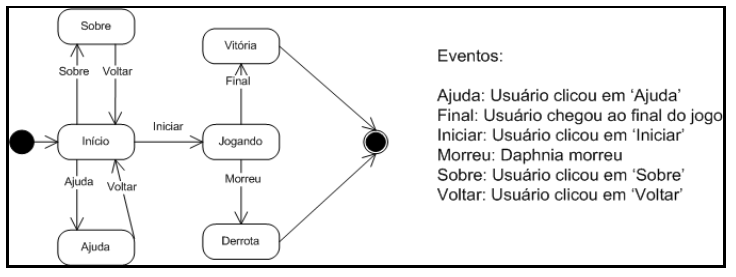

Figura 2: Diagrama de Estados do Jogo

\subsection{Edição gráfica}

Foram utilizados, principalmente, dois softwares livres de edição gráfica para o desenvolvimento do jogo:

- Inkscape: Um editor gráfico vetorial Open Source, com capacidade similar ao Illustrator, CorelDraw ou Xara X [15]; e
- Gimp: Software distribuído gratuitamente para tarefas de retoque em fotos e composição de imagens [16].

Tanto para o Gimp quanto para o Inkscape foram utilizadas as versões portáteis (que não necessitam instalação) para Windows.

Um gráfico vetorial é uma descrição independente de resolução das formas reais e objetos vistos em uma imagem. Uma engine de rasterização utiliza esta informação para determinar como criar e desenhar cada linha ou curva em qualquer nível de resolução [15]. Em contraste com o gráfico vetorial, existem os gráficos de bitmap, que possuem uma resolução fixa e são armazenados como uma grade de pixels [16].

Os desenhos dos personagens foram feitos a mão, digitalizados e, posteriormente, vetorizados e coloridos no Inkscape. Para o desenho, foi utilizada a ferramenta Curvas de Bézier no InkScape, que se assemelha a uma caneta, permitindo que sejam desenhadas curvas e linhas. Após o tracejado ser finalizado, as cores foram escolhidas utilizando-se a paleta de cores. Finalizadas as imagens, as mesmas foram exportadas para um formato de imagem de bitmap, o PNG. Este formato foi escolhido por suportar transparência, não permitindo que apareça um quadro branco em volta do desenho exportado (Figura $3 \mathrm{a}$ e $3 \mathrm{~b}$ ).

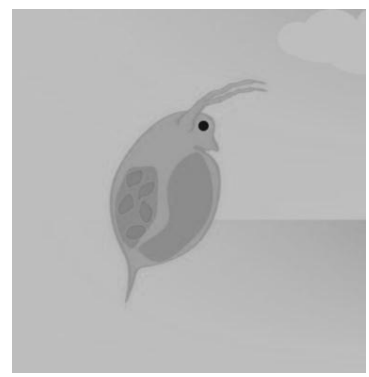

(a)

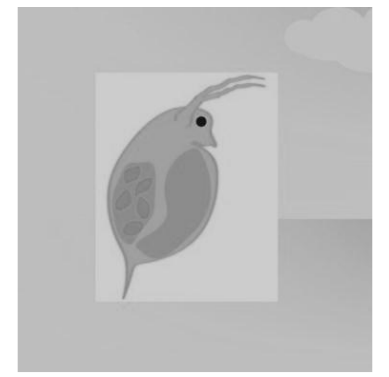

(b)
Figura 3: Exemplo de imagem da Daphnia a) com transparência; e b) sem transparência.

Finalizados os personagens, foi desenvolvido o cenário do jogo. O cenário foi elaborado utilizando-se o Gimp para criação de imagens bitmap. Diferentemente do desenho vetorial, o GIMP oferece possibilidades de criação de texturas essenciais para criação de um cenário mais realista. Essas texturas utilizam uma combinação de efeitos diretamente utilizada sobre os pixels das imagens, fazendo com que uma simples imagem preenchida com uma cor ganhe uma textura sólida. A principal paleta utilizada foi a Filters do Gimp, que fornece varias opções de filtros. Foram utilizados, principalmente, os filtros Artistic, Noise, Distort e Render, assim como degradê de cores para dar efeito de profundidade e volume. 
O Gimp também oferece organização da imagem trabalhada em camadas, facilitando a sobreposição de imagens e texturas, onde cada camada possui uma parte diferente da imagem. Cada parte do cenário foi desenvolvida em diferentes camadas: céu, terra, grama e água.

Por último, foram confeccionados os itens da interface geral, como os botões e os ícones do jogo. Estes elementos também foram criados com o Inkscape, sendo desenhados e depois exportados em PNG.

A construção dos desenhos, e do jogo por conseguinte, sempre teve em vista três pontos, que precisaram ser equilibrados:

- Fidelidade: buscou-se manter as imagens e proporções dos personagens bastante próximos do real;

- Motivação: os personagens do jogo devem ser motivadores para seus usuários, crianças e jovens que já tem muito contato prévio com jogos e que rejeitariam conceitos muito diversos do que já estão habituados;

- Educacional: buscou-se transformar o jogo em um ambiente com um conjunto oportunidades de aprendizado, trabalhando os valores e conceitos da área de ecotoxicologia.

A personagem principal, a Daphnia, foi feita a partir de uma foto (Figura 4a). A partir deste material, foram analisadas as principais características da Daphnia, para que uma estilização pudesse ser feita (Figura $4 \mathrm{~b}$ ).

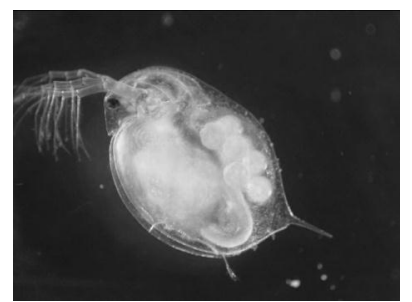

(a)

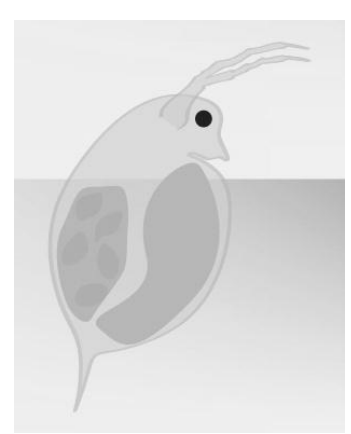

(b)
Figura 4. a) Foto do micro-crustáceo Daphnia [17] e b) desenho estilizado para o jogo.

O segundo personagem criado foi o primeiro antagonista da Daphnia, o peixe. Sua função é servir como obstáculo para a Daphnia durante o jogo. Foram analisadas várias imagens, principalmente desenhos, sendo descartadas as imagens em que o peixe aparece de forma mais agressiva, pois o jogo não quer incitar uma visão de personagem bom ou ruim, dado que são todos membros de um ecossistema equilibrado.Assim como a Daphnia, o desenho do peixe foi concebido de forma estilizada (Figura 5).

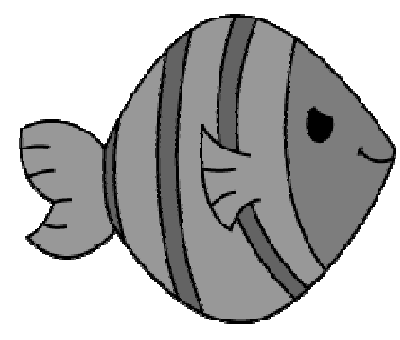

Figura 5: Peixe, o primeiro antagonista do jogo.

Outro antagonista da Daphnia, a Hidra, também foi desenhada a partir de uma foto (Figura 6). A Hidra também foi feita de forma estilizada, incluindo um rosto para que se torne parte do estilo gráfico do jogo.

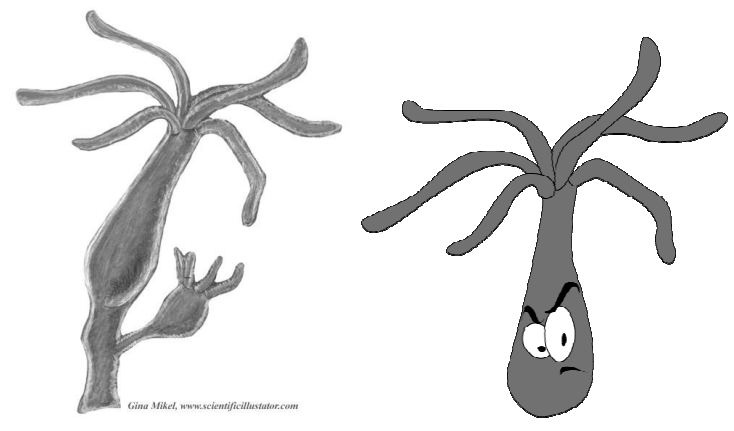

Figura 6: a) Imagem da Hidra [18]; e b) Desenho estilizado da Hidra.

A última personagem criada para o jogo nesta primeira parte do projeto é a Tecnóloga em Saneamento Ambiental (batizada como Jill, Figura 7). Sua função é apoiar o jogador. Este desenho foi concebido originalmente para o jogo. A personagem Jill pode ser vista como uma "facilitadora" do aprendizado, uma vez que se limita a oferecer apoio quando o usuário solicita, sem ter um controle ativo do jogo.

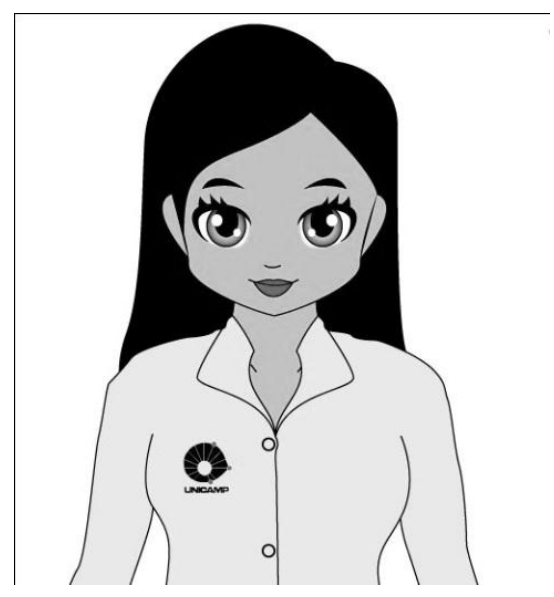

Figura 7: Tecnóloga em Saneamento Ambiental. 
Finalizados os personagens principais do jogo, o próximo elemento desenvolvido foi a Indústria (Figura 8), que tem a função de liberar concentrações de poluição na água, sendo mais um obstáculo para a Daphnia.

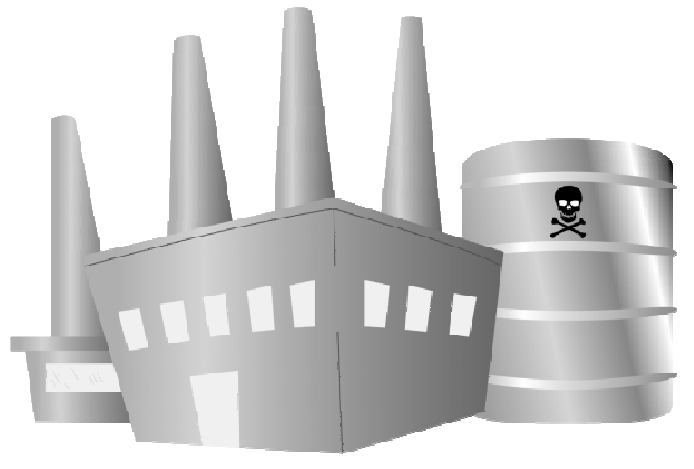

Figura 8: Indústria poluidora do jogo.

Para animar os elementos, definiu-se um quadro ( $f r a-$ me) inicial, que foi usado como base para a movimentação das outras imagens. No caso do peixe, a animação restringe-se à única movimentação referente à boca (Figura 9).

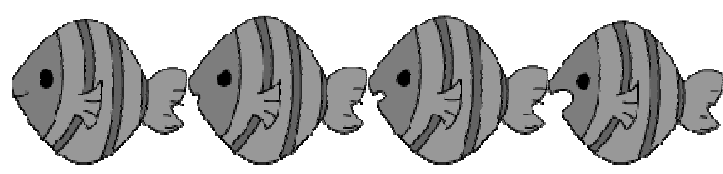

Figura 9: Quadros do peixe.

\subsection{Design da interface}

O Design de jogos é um processo artístico e técnico [19]. A parte artística consiste na criação da interface geral do jogo, incluindo suas telas, transições e visual. Para o desenvolvimento, foram utilizados três conceitos básicos para o desenvolvimento de interfaces [20]:

- Usabilidade: a interface atende às expectativas do usuário? A interação é feita de forma eficiente?;

- $\quad$ Funcionalidade: diz respeito às funções que devem ser inseridas na interface. Muitas vezes, oferecer menos funcionalidades é melhor, exibindo as informações mais importantes de um modo padronizado; e

- $\quad$ Estética e comunicação visual: utilização de elementos gráficos como ícones, botões e textos estilizados e utilização do espaço para alocar esses elementos.

Estes conceitos foram explorados tanto para as telas quanto para a mecânica do jogo em si. A utilização dos conceitos de usabilidade, funcionalidade e estética no processo de construção do jogo está explicitada nas próximas subseções.

\subsubsection{Usabilidade}

O jogo foi inicalmente concebido para jovens em idade de ingressar na universidade, mas testes preliminares apresentaram resultados positivos para seu uso com crianças pequenas, tendo o primeiro contato com conceitos de ecologia, como poluição.

Primeiramente, foram analisados os meios para se adaptar a esta heterogeneidade de usuários, criando uma interface no geral mais fácil de ser manipulada, de fácil aprendizado. Para isso, foram tomadas como base três das dez Heurísticas de Nielsen para o desenvolvimento de interfaces gráficas [21]:

- Consistência e padrões: padronização da informação para o usuário. Evitar o uso de sinônimos;

- Design minimalista: colocar apenas o necessário, evitando informações irrelevantes ou raramente necessárias. Cada unidade extra de informação irrelevante compete diretamente com unidades de informação relevante. Isso faz com que a visibilidade relativa seja comprometida; e

- $\quad$ Ajuda e documentação: fornecer ajuda e documentação para orientar o usuário. Essas informações devem ser acessadas de forma rápida e eficiente. Devese disponibilizar apenas o necessário.

São exemplos de design minimalista a tela inicial (Figura 13) onde apenas os botões Iniciar, Ajuda e Sobre estão disponíveis. As telas Ajuda e Sobre também são ilustrativas, tendo apenas um botão para retornar para a tela inicial.

Para proporcionar uma melhor alocação para os elementos na tela, foi utilizada a "regra dos terços". Segundo esta "regra", a tela é dividida em três terços verticais e três terços horizontais. As intersecções destas linhas imaginárias sugerem opções para a colocação do centro de interesse, ou seja, destacando os pólos de atenção visual [22]. Na tela inicial, os botões foram colocados no terço inferior da tela, sendo os outros dois terços ocupados pelo logotipo do jogo. Durante o jogo, a maior parte da tela (dois terços inferiores) é ocupada pelo rio, onde a Daphnia ira se locomover.A locomoção é feita através das setas do teclado e a interação com os itens se dá através dos ícones exibidos na tela (também possuindo interação através do teclado).

\subsubsection{Funcionalidade}

Daphnia World é um jogo de plataforma, apresentan- 
do, de acordo com Santos e do Vale [23], uma maior interação com o jogador, uma vez que os atores componentes da ação reagem às decisões adotadas pelo usuário.

De acordo com Crawford [19], os jogos podem ser comparados a uma história. A diferença entre os dois é que uma história apresenta os fatos em uma sequência imutável, enquanto que os jogos apresentam uma vasta árvore de sequências, permitindo que o jogador crie sua própria história através de escolhas.

Buscando disponibilizar uma primeira versão do jogo de forma mais ágil, baseando-se no contexto proposto por Crawford [19], apenas funcionalidades básicas e essenciais foram inseridas, evitando que a árvore de sequências se tornasse muito complexa.

Após uma partida, o usuário poderá iniciar uma nova, caso tenha vencido ou tenha sido derrotado. Em ambos os casos, é exibida uma tela, fornecendo saída para o jogador.

\subsubsection{Estética}

No que diz respeito à estética, primeiramente, foram escolhidas as cores principais através de uma análise dos tipos de cores: primárias, secundárias e terciárias, descritas a seguir [24]:

- $\quad$ Primárias: são elementares, não podendo ser produzidas por misturas. Existem apenas três cores primárias:

○ Azul: Cor fria, calma e reservada. Está presente em todos os sombreados, servindo como balança para o vermelho e o amarelo;

o Amarelo: A mais brilhante das cores primárias;

o Vermelho: A cor mais quente e agressiva. Todas as cores que contém vermelho são consideradas quentes;

- Secundárias: as combinações de cores primárias formam uma cor secundária (também chamada de cor binária);

- Terciárias: combinando as três cores primárias em tons iguais, o resultado é cinza. Porém, se uma cor predominar sobre as outras duas, o resultado será um tom acinzentado da cor predominante.

A partir desta análise, foi possível identificar quais cores ficariam adequadas à estética do jogo. $\mathrm{O}$ azul, por exemplo, como cor primária, é predominante no ambiente, participando então na composição do verde, que também é utilizado no cenário. Todas as cores do jogo foram selecionadas usando como base as relações para tornar o ambiente mais harmônico.
As cores do letreiro, contendo o nome do jogo, foram baseadas em temas de jogos infantis de plataforma, como Super Mario World [23]. Os botões foram feitos na mesma fonte do logotipo do jogo, tendo como contraste o azul e o verde, ressaltando o tema ecologia.

O cenário principal do jogo é um rio (Figura 10), onde a Daphnia se locomove. A partir deste cenário, são localizados os elementos principais da interface, como a barra de vida, a contagem de moedas do jogo e os símbolos com os itens a disposição do jogador (Figura 11).

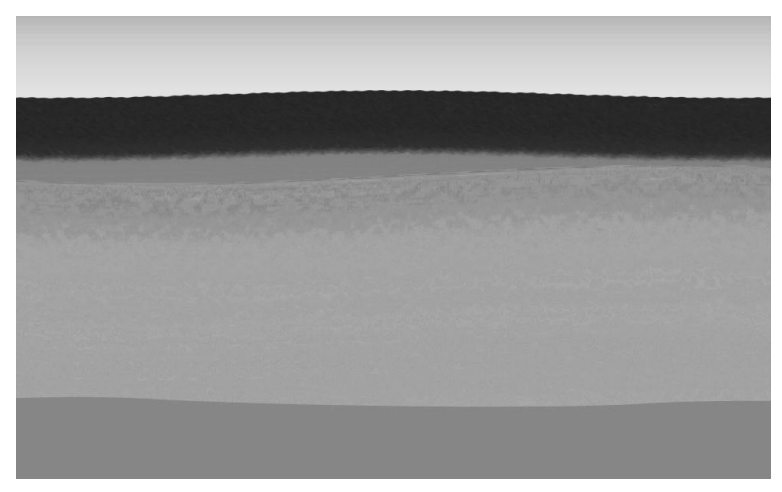

Figura 10: Efeito de água, grama e terra feitos no Gimp através de filtros. (a)

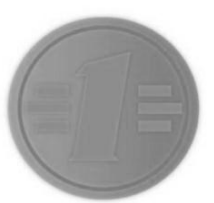

(c)

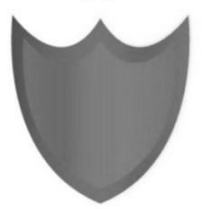

(d)

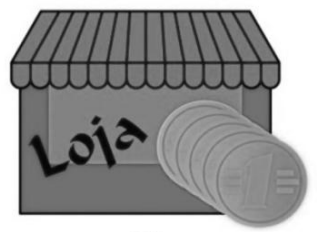

(b)

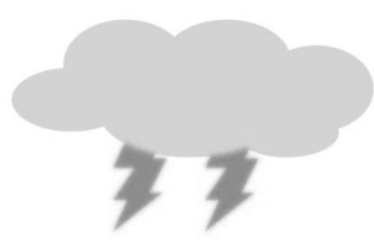

(e)
Figura 11: Elementos do jogo: a) Barra de vida; b) ícone da loja; c) moeda; d) ícone do escudo; e e) ícone de chuva.

O objetivo da boa disposição das informações é facilitar a tomada de decisões do usuário, tornando-a uma ação precisa e não dificultando a visibilidade do cenário do jogo, onde ocorre a ação.

A estética e disposição dos menus do jogo seguem um 
padrão proposto por Luz [25] apresentado na Figura 12.

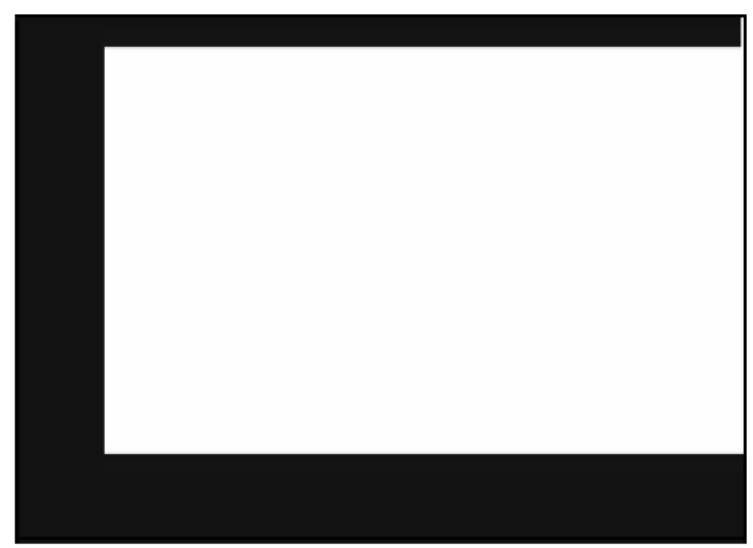

Figura 12: Áreas mais utilizadas para interface de menus e outras informações [25].

\section{Resultados}

Para auxiliar o ensino de conceitos associados à ecotoxicologia foi criado o jogo Daphnia World. Neste jogo, o usuário deve controlar a personagem Daphnia de tal forma que ela percorra um rio, enfrentando inimigos naturais e poluição, até chegar em um local, denominado santuário, onde possa se reproduzir [26].

A primeira versão do jogo foi disponibilizada livremente na internet ${ }^{1}$ a partir de dezembro de 2010. Nesta versão, o usuário é apresentado inicialmente à tela ilustrada na Figura 13. Na tela inicial o jogador pode optar por começar o jogo (estado "Jogando"), verificar a ajuda (estado "Ajuda") ou ainda ler informações sobre o jogo (estado "Sobre"). Ao selecionar o botão Ajuda é apresentada uma tela de texto simples com os principais controles do jogo. Se selecionar o botão Sobre, é apresentada uma tela com o nome dos professores e dos alunos que participaram da primeira versão do jogo. Ao selecionar o botão Iniciar, é apresentada a tela ilustrada na Figura 14.

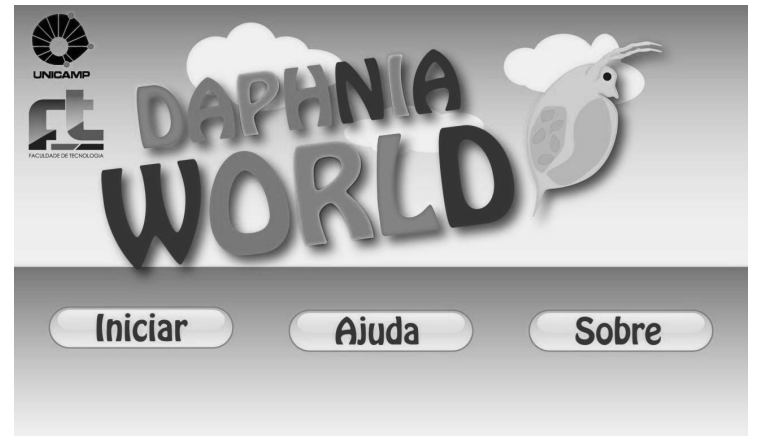

${ }^{1}$ http://www.ft.unicamp.br/liag/labslife/daphnia/
Figura 13: Daphnia, barra de informações e botões

A Figura 14 ilustra a tela principal do jogo, em seu início. Na parte superior da tela fica a personagem "Tecnóloga", que foi inserida no jogo com o objetivo repassar conceitos e conteúdos aos usuários e também ajuda-los no jogo. No momento inicial a Tecnóloga apresenta a Daphnia e os objetivos do jogo: controlar a Daphnia para esta nadar ao longo do rio, da foz até sua nascente (da esquerda para direita no jogo), comendo algas e coletando moedas (ambas presentes no centro da Figura 14) no caminho e buscando evitar os predadores (peixes e hidras) e a poluição. A barra azul abaixo mede o nível de "saúde" da Daphnia: ela perde "saúde" ao esbarrar em seus predadores e ao passar por água muito quente ou poluída. A Daphnia ganha "saúde" comendo algas. E no extremo inferior direito há um contador de moedas coletadas pela Daphnia, que servirão para comprar itens.

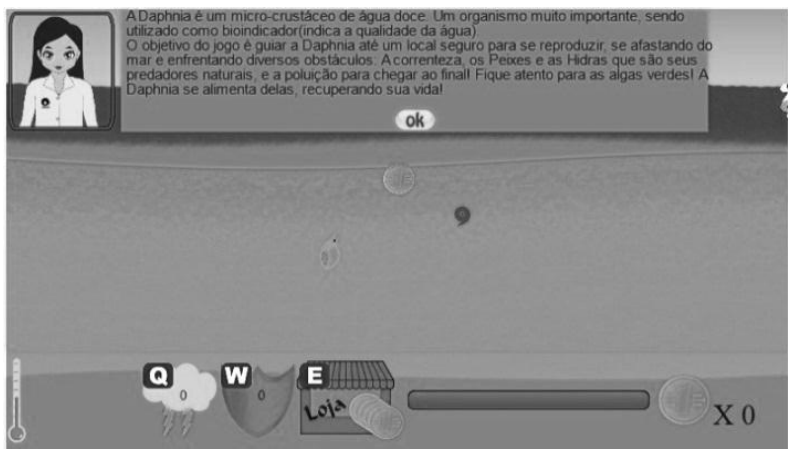

Figura 14: Início do jogo: tecnóloga fazendo os comentários iniciais do jogo acima, Daphnia, moeda e alga no centro do rio, medidor de temperatura da água à esquerda, ações disponíveis ao centro, barra de informações e contador de moedas coletadas na parte inferior direita

A Figura 15 ilustra o momento em que a Daphnia é confrontada com uma emissão de uma indústria poluente. A personagem tecnóloga indica que é uma emissão de cobre e se coloca a disposição para apresentar maiores informações. Ao longo do jogo existem vários diferentes tipos de emissões despejadas no rio. O jogador deve tentar fazer com que a Daphnia passe pela região onde há a emissão o mais rapidamente possível, tentando evitar ao máximo o contato com os poluentes. A Figura 16 mostra a Daphnia passando por um outro tipo de poluição (zinco) e tendo sua saúde prejudicada (barra azul diminuindo).

Buscando tornar o jogo mais motivador, foi criada a funcionalidade de coleta de moedas e a loja. Na loja podem ser comprados "poder de chuva" e escudos, cada qual com seu valor em moedas. A Figura 17 ilustra a tela correspondente à loja. 


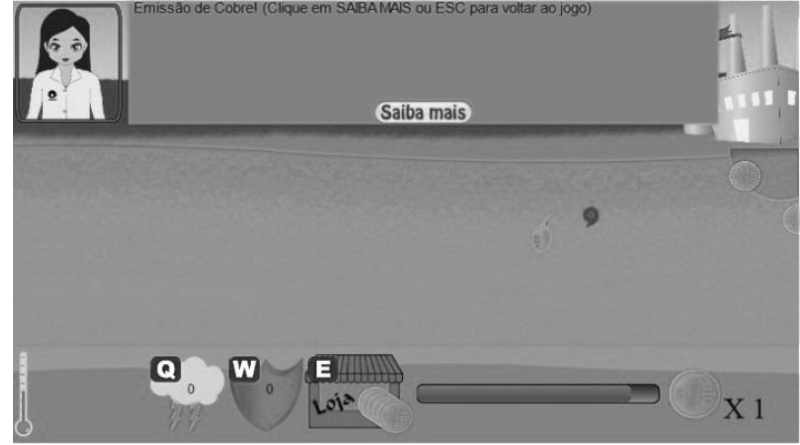

Figura 15: Daphnia é confrontada com uma emissão tóxica, com a personagem tecnóloga apresentando qual o tipo de poluente e se dispondo a explicar melhor sobre ela

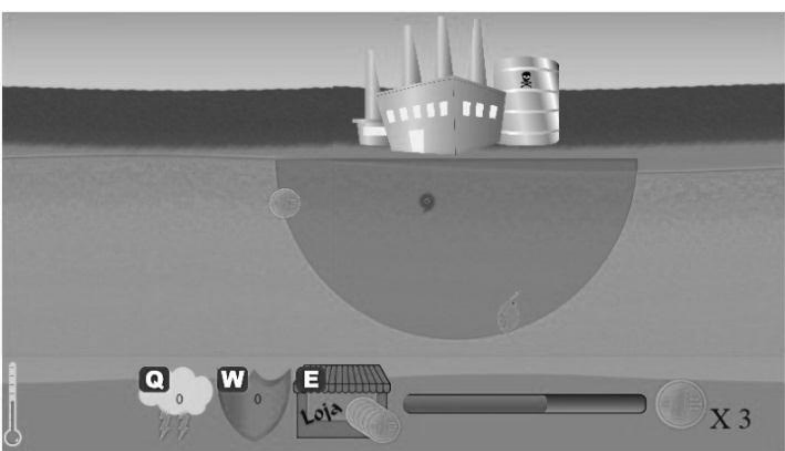

Figura 16: Daphnia passando por uma emissão de zinco

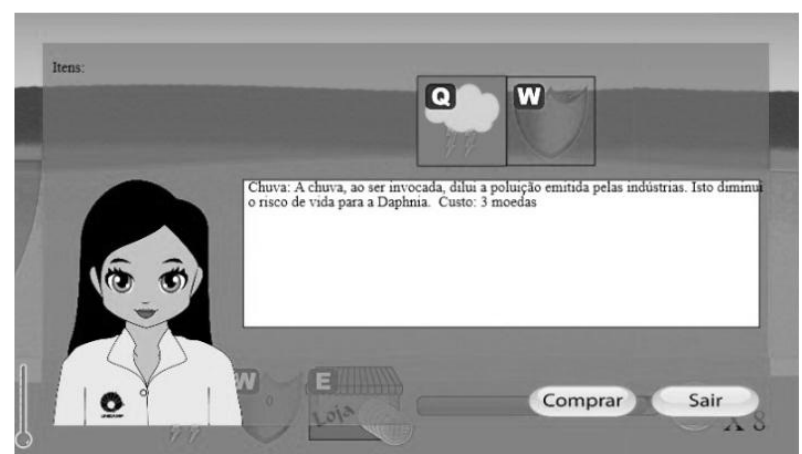

Figura 17: Loja

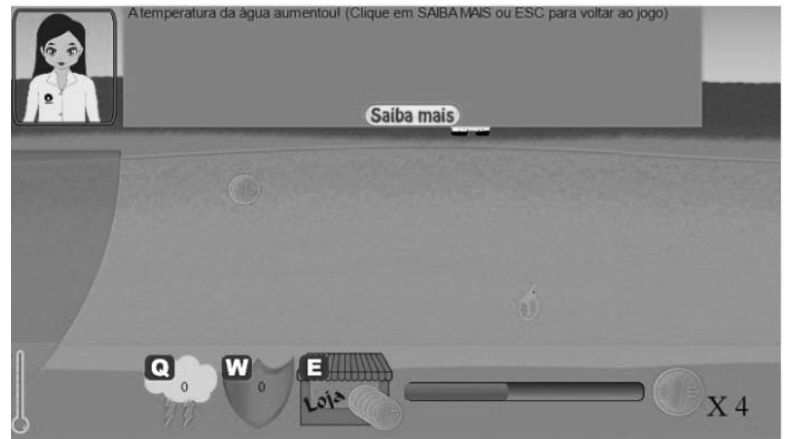

Figura 18: Momento em que a temperatura da água aumenta e tecnóloga apresenta a situação

A água do rio, em alguns momentos, se aquece, conforme ilustrado na Figura 18. A tecnóloga, se solicitado pelo usuário selecionando o botão "Saiba Mais", pode explicar os motivos desse aquecimento. Uma forma de evitar a perda de "saúde" da Daphnia com esse aquecimento, é a Daphnia exercer o "poder de chuva" comprado anteriormente na loja. Essa chuva também ajuda a dissolver poluentes. A Figura 19 ilustra um momento onde o "poder de chuva" foi exercido pelo usuário.

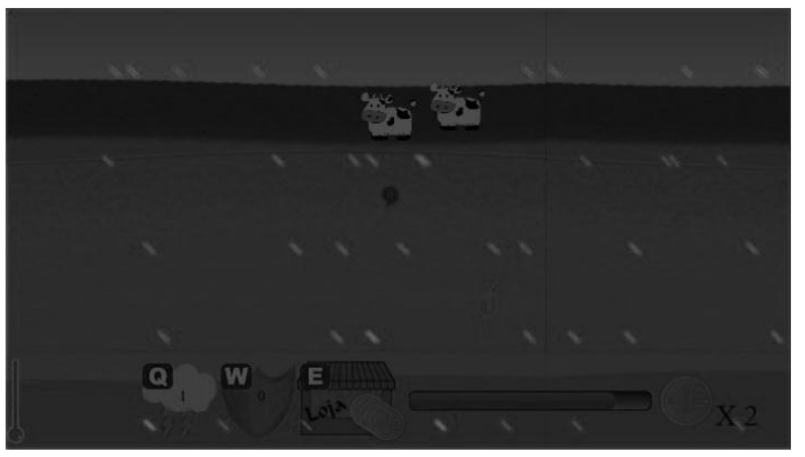

Figura 19: Chuva que ocorre quando usuário usa o "poder da chuva" que comprou na loja

Além de enfrentar a poluição e aquecimento da água, a Daphnia enfrenta seus inimigos naturais no caminho até o ponto onde pode se reproduzir. Eles são os peixes (ilustrados na Figura 20) e a hidra (ilustrada na Figura 21). Se a Daphnia encostar em um dos seus antagonistas, perde parte de sua "saúde". Se tiver sido comprado o escudo na loja, ele pode ser usado e protegerá temporariamente a Daphnia de seus antagonistas.

Uma vez que a Daphnia consiga ultrapassar todas as dificuldades apresentadas ao longo do curso do rio, ela chegará ao santuário, ponto onde poderá reproduzir, ilustrado na Figura 23.

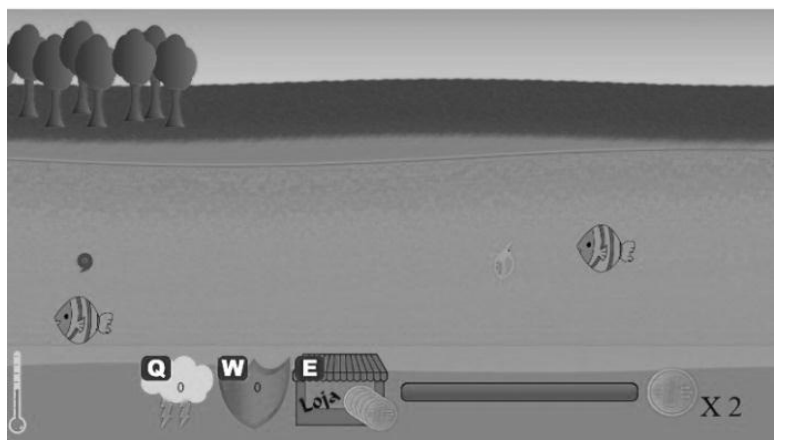

Figura 20: Daphnia encontrando os peixes antagonistas 


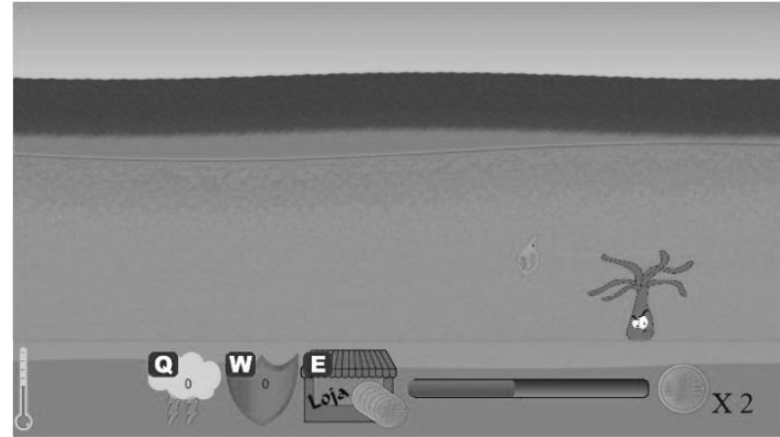

Figura 21: Daphnia encontrando a Hidra

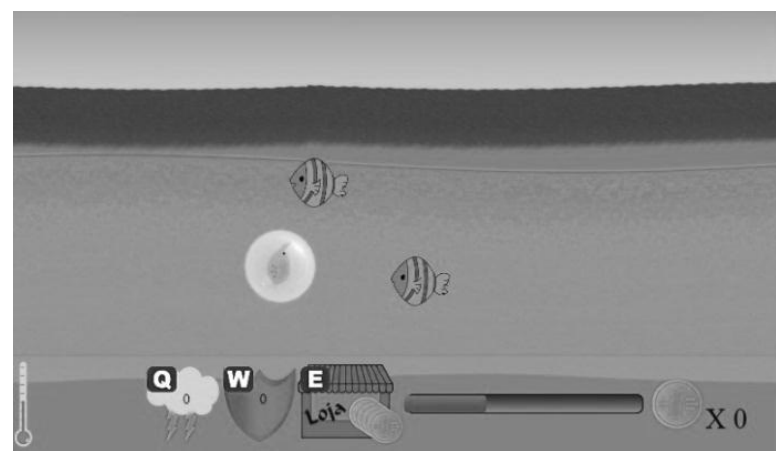

Figura 22: Daphnia usando escudo ao encontra os peixes antagonistas

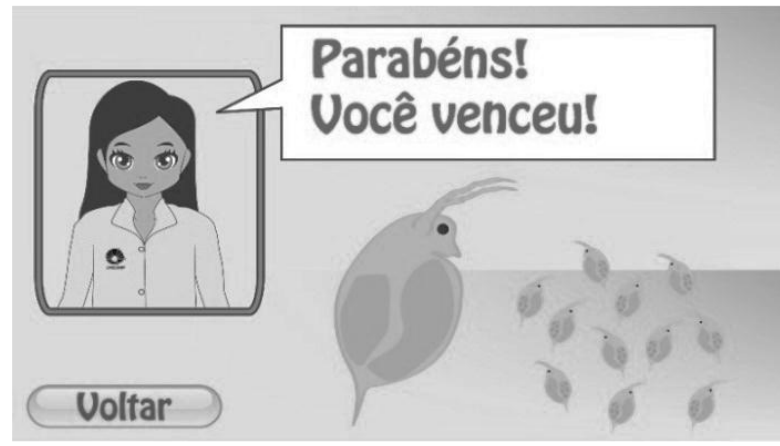

Figura 23: Daphnia chega ao ponto onde irá procriar

\section{Conclusão}

Este trabalho apresentou uma experiência de desenvolvimento de um jogo voltado para a formação de conceitos de ecotoxicologia de forma construtivista.

O desenvolvimento de jogos em HTML5, usando o Javascript como linguagem de programação e o elemento canvas para a exibição mostrou-se possível. O elemento canvas possui uma API com recursos para o desenho de elementos 2D para a criação de um jogo no estilo Daphnia World. Com a adição deste elemento e sua poderosa API, o HTML5 mostra-se adequado para o desenvolvi- mento de jogos educativos. A primeira versão do jogo atingiu aos objetivos planejados. Este resultado mostrou a possibilidade de se desenvolver jogos educativos em HTML5, uma plataforma livre, aberta e padronizada internacionalmente.

O jogo foi inicialmente concebido para ser usado com jovens em idade de ingresso em universidades, para ser uma ferrmanenta na apresentação do conceito de ecotoxicologia. Mas testes iniciais feitos com crianças em idade pré-escolar também apresentaram resultados promissores: com um uso bastante pontual, houve um claro interesse das crianças por conceitos como poluição, o que pode ser um uso interessante na formação dos valores dessas crianças. Esta nova possibilidade de uso trás consigo novos desafios para a continuidade do projeto.

Como continuidade, é necessário realizar testes formais do uso do jogo com crianças e jovens, buscando identificar oportunidades de melhorias. A engine construída também poderia ter mais classes desenvolvidas, oferecendo por exemplo um sistema de colisão e um controle de estados automatizado. Há também a possibilidade de agregar inteligência artificial à tecnóloga, de forma a fazer com que ela consiga monitorar o usuário jogando, identificando possíveis estratégias que não estão sendo utilizadas e ajudadando-o a atingir a meta. A tecnóloga também poderia interagir com o usuário em linguagem natural e falada, o que seria bastante importante para o uso do jogo com crianças em idade pré-escolar.

\section{Referências Bibliográficas}

[1] Williams, P. L. James, R. C. Roberts, S. M. (2000). "Principles of Toxicology: Environmental and Industrial Applications". $2^{\mathrm{a}}$ ed, ilustrada. ISBN:0471293210, John Wiley and Sons, Estados Unidos. 2000.

[2] Monro, A. M. (2001) "Toxicologists - come out and educate!". TRENDS in Pharmacological Sciences, vol 22, n. 6, pg 325-327. 2001.

[3] Jonczyk, E. Gilron, G. "Acute and Chronic Toxicity Testing with Daphnia SP”. In: Blaise, C. Ferárd, J. F. (Ed.) Small-Scale Freshwater Toxicity Investigations: Toxicity test methods. Vol. 1. ISBN: 140203119X, Springer Science \& Business. 2005.

[4] Valente, J. A. (1993). "Por que o computador na educação". Campinas. Gráfica Central da Unicamp, pg 24-44.

[5] Campos, F. C. A. Rocha, A. R. C. (1998). "Design Instrucional e Construtivismo: em Busca de Modelos para o Desenvolvimento de Software". Publicado nos Anais do IV Congresso da Rede Iberoamericana de Informática Educativa (RIBIE), Brasí- 
lia. 1998.

[6] Bittencourt, J. R. Giraffa, L. M. (2003) "Modelando Ambientes de Aprendizagem Virtuais utilizando Role-Playing Games". Publicado nos Anais do XIV Simpósio Brasileiro de Educação (SBIE), Rio de Janeiro. 2003.

[7] Rieber, L. P. (1996). "Seriously Considering Play: Designing interactive learning environments based on blending of microworlds, simulations, and games. Educational Technology Research \& Development", n. 44, pg. 43-58. 1996.

[8] NetApplications. (2011). Browser Market Share. Disponível em http://marketshare.hitslink.com/report.aspx?qprid= 0 . acesso em Junho de 2011.

[9] Kuntze, U. (2010). Aplicações Ricas com Ajax. Disponível em http://projetos.inf.ufsc.br/arquivos_projetos/projeto _482/Aplica\%E7\%F5es_Ricas_com_Ajax_\%96_A rtigo.pdf . acesso em Setembro de 2010.

[10] Wichary, M. Delgado, E. (2010) HTML5: "Web Development to the next level". Apresentado na Google IO 2010.

[11] World Wide Web Consortium [W3C, 1998]. "Document Object Model (DOM) Level 1 Specification. Versão 1.0”. Disponível em: http://www.w3.org/TR/REC-DOM-Level-1 . Publicado em Outubro de 1998.

[12] Lie, H. W. Bos, B. (1999) "Cascading Style Sheets: designing for the Web". 2 ed, ISBN:0201596253, Addison-Wesley. 1999.

[13] ECMA-Internacional (ECMA, 2009). "ECMAScript Language Specification". $5^{\mathrm{a}}$ ed. Disponível em http://www.ecmainternational.org/publications/files/ECMAST/ECMA-262.pdf. acesso em Setembro de 2010. Publicado em Dezembro de 2009.

[14] Bishop, L. Eberly, D. Whitted, T. Finch, M. Shantz, M. (1998). "Designing a PC game engine". In: Computer Graphics and Applications, IEEE , vol.18, no.1, pp.46-53, Jan/Feb 1998.

[15] Inkscape. Disponível em: http://inkscape.org. acesso em: 23 jan 2010.

[16] Gimp. Disponível em: http://www.gimp.org. acesso em: 23 jan 2010.

[17] Daphnia Magna. Disponível em: http://www.kuleuven-kortrijk.be/facult/ wet/biologie/pb/kulakbiocampus/insectenongewervel-
den/vijverfauna/zooplankton/Daphnia\%20magna/ Daphnia\%20magna.htm . Acesso em: 30 mar. 2010.

[18] ScientificIllustrator. Disponível em http://www.scientificillustrator.com/illustration/mi croscopic/hydra.html. acesso em: 30 mar de 2010. 2010 .

[19] Crawford, C. The art of computer game design. 1984. Disponível em: http://arcarc.xmission.com/Magazines\%20and\%20 Books/Art\%20of\%20Game\%20Design.pdf. acesso em: 18 jan. 2011.

[20] Vertelney, L.; Arent, M.; Lieberman, H..apud Borges, M. A. F. O Design Centrado no Aprendiz no Sistema Jonas: uma Experiência de Desenvolvimento de um Sistema para Formação na Empresa. Campinas: Instituto de Computação, Universidade Estadual de Campinas, 1997. (Dissertação, Mestrado em Ciência da Computação).

[21] Nielsen, J.Ten Usability Heuristics.2005. Disponível em: http://www.useit.com/papers/ heuristic/heuristic_list.html. acesso em: 5 jan. 2011.

[22] Nascimento, A. S. B.; Torezani, J. N. O textolegenda e a fotografia: Informação textual e imagética no jornalismo on-line. In: Congresso Nacional de Representação de Linguagens e Representações: Linguagens e Leituras, I, 2009.

[23] Santos, C. L.. Do Vale, F. S. Jogos eletrônicos na educação: Um estudo da proposta dos jogos estratégicos. Monografia (Bacharel em Ciência da Computação). Universidade Federal de Sergipe, 2006.

[24] Robison, F. H. Color \& Character: A Contemplation of the Four Divine Qualities. Lulu.com, ISBN: 1411687752. 2006.

[25] Luz, M. H. G. C. apud Santos, C. L.; Do Vale, F. S. Jogos eletrônicos na educação: Um estudo da proposta dos jogos estratégicos. $111 \mathrm{f}$. Monografia (Bacharel em Ciência da Computação). Universidade Federal de Sergipe, 2006.

[26] Bispo, D. M. Zabeu, M. S. Umbuzeiro, G. A. Borges, M. A. F. (2010). "Jogo Computacional para Introdução à Toxicologia Ambiental”. Pôster publicado no XXI Simpósio Brasileiro de Informática na Educação (SBIE). Novembro de 2010. 